\title{
Coronal Alignment of the Lower Limb and the Incidence of Constitutional Varus Knee in Korean Females
}

\author{
Moo-Ho Song, $\mathrm{MD}^{1}$, Seong-Ho Yoo, $\mathrm{MD}^{1}$, Suk-Woong Kang, $\mathrm{MD}^{1}$, Yeong-Joon Kim, $\mathrm{MD}^{1}$, Gyu-Taek Park, \\ $\mathrm{MD}^{1}$, and Yong-Seon Pyeun, $\mathrm{MD}^{2}$ \\ Departments of ${ }^{1}$ Orthopaedic Surgery and ${ }^{2}$ Radiology, Daedong General Hospital, Busan, Korea
}

\begin{abstract}
Purpose: In total knee arthroplasty (TKA), it is important to restore neutral mechanical alignment. The purpose of this study was to assess whether the lower limb alignment is neutral in healthy Korean females and investigate the incidence of constitutional varus knees among them.

Materials and Methods: Weight-bearing full-leg standing radiographs were obtained from 118 healthy females between the ages of 20 to 39 years. One radiologist and two orthopaedic surgeons measured the hip-knee-ankle angle (HKAA), medial proximal tibial angle (MPTA), and femoral anatomic mechanical angle (FAMA) on the radiographs and compared with the traditional gold standard HKAA of $0^{\circ}$, MPTA of $3^{\circ}$ varus, and FAMA of $6^{\circ}$. Results: The interobserver reliability of the three independent observers was high $(\mathrm{p}<0.001)$. The HKAA of the study subjects $\left(1.35^{\circ} \pm 2.04^{\circ}\right)$ was significantly different from the standard HKAA of $0^{\circ}(\mathrm{p}<0.001)$, but no statistically significant difference was observed in the MPTA $\left(-3.18^{\circ} \pm 1.61^{\circ}\right)$ and FAMA $\left(5.99^{\circ} \pm 0.70^{\circ}\right)$ from the standard values ( $\mathrm{p}=0.083$ and $\mathrm{p}=0.887$, respectively). The incidence of constitutional varus alignment was $20.34 \%$. Conclusions: In Korean females, the mechanical axis of the lower limb was not neutral and the incidence of constitutional varus alignment was slightly higher than that in Western females. We believe that these findings should be taken into consideration in planning reconstructive surgery of the knee, such as TKA, unicompartmental knee arthroplasty, and high tibial osteotomy.
\end{abstract}

Keywords: Lower extremity, Knee, Mechanical axis, Constitutional varus

\section{Introduction}

Restoration of neutral mechanical alignment of the lower limb in total knee arthroplasty (TKA) has been demonstrated as a key determinant of the longevity of knee implants in various studies $^{1,2)}$. In a neutrally aligned limb, the mechanical axis passes through the center of the knee joint, thereby minimizing the risk of component wear and loosening ${ }^{3-5)}$. However, the importance

Received August 7, 2014; Revised November 30, 2014;

Accepted December 26, 2014

Correspondence to: Seong-Ho Yoo, MD

Department of Orthopaedic Surgery, Daedong General Hospital, 187

Chungnyeol-daero, Dongnae-gu 607-711, Busan, Korea

Tel: +82-451-554-8996, Fax: +82-451-553-7575

E-mail: mhsong21@hanmail.net

This is an Open Access article distributed under the terms of the Creative Commons Attribution Non-Commercial License (http://creativecommons.org/licenses/by-nc/3.0/) which permits unrestricted non-commercial use, distribution, and reproduction in any medium, provided the original work is properly cited. of neutral mechanical alignment is based on the premise that the mechanical axis passes through the center of the knee joint, the medial proximal tibial angle (MPTA) is $3^{\circ}$, and the femoral anatomic mechanical angle (FAMA) is $6^{\circ}$ in the normal knee. Furthermore, recent studies have shown that a great extent of medial soft tissue release is required for restoration of neutral mechanical alignment in patients with constitutional varus knees $\left(\geq 3^{\circ}\right.$ varus alignment) and such patients are more common than previously thought, specifically $32 \%$ in males and $17.2 \%$ in females in a western population ${ }^{6}$. In this study, we investigated whether the lower limb alignment was neutral in healthy Korean females without symptoms of knee osteoarthritis and assessed the incidence of constitutional varus knees among them.

\section{Materials and Methods}

This study was conducted with our Institutional Review Board approval on 121 female volunteers between the ages of 20 to 39 
years who had been working at our hospital. Informed consent was obtained from all volunteers prior to study and knee joint pain and history of trauma were defined as exclusion criteria. Three of the volunteers were excluded due to femoral head deformity, rotational deformity of the femur, and congenital tibial deformity. Ultimately, 118 patients were available for the assessment of both lower limbs. Their mean age was 26.76 years and the mean body mass index (BMI) of $21.62 \mathrm{~kg} / \mathrm{m}^{2}$ was within the normal range (Table 1 ). Weight-bearing full-leg standing radiographs were taken with the patients standing barefoot. To preclude errors due to rotation, the medial borders of the heels and the first metatarsophalangeal joints of both foot were positioned to be in full contact, with the patella facing forward. The distance between the source of radiation and the patient was $300 \mathrm{~cm}$. With three $17 \times 17$ inch cassettes placed behind the hips, knees, and the feet, radiographs were taken at $100 \mathrm{mAs}, 64 \mathrm{mAs}$, and 32 $\mathrm{mAs}$, respectively. The radiographic images were obtained using INNOVISION ver. 2.0 program (DK Medical Systems Co., Pyeongtaek, Korea). One radiologist and two orthopaedic surgeons

Table 1. Patient Characteristics

\begin{tabular}{lc}
\multicolumn{1}{c}{ Variable } & Mean \\
\hline No. of patients $(\%)$ & $118(100)$ \\
Age $(\mathrm{yr})$ & $26.76 \pm 4.33$ \\
Height $(\mathrm{cm})$ & $161.51 \pm 4.69$ \\
Weight $(\mathrm{kg})$ & $56.40 \pm 10.01$ \\
Body mass index $\left(\mathrm{kg} / \mathrm{m}^{2}\right)$ & $21.62 \pm 3.73$ \\
\hline
\end{tabular}

Values are presented as mean \pm standard deviation.

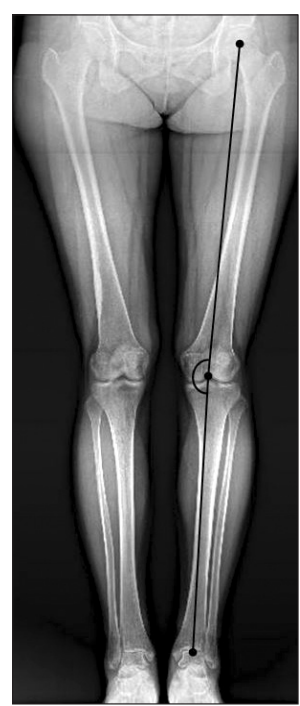

Fig. 1. Hip-knee-ankle angle. independently measured the hip-knee-ankle angle (HKAA), MPTA, and FAMA in each patient for comparison with the gold standard values (HKAA, $0^{\circ}$; MPTA, $3^{\circ}$ varus; and FAMA, $6^{\circ}$ ). The possible causative factors of constitutional varus knees, femoral bowing angle (FBA) and mechanical lateral distal femoral angle (mLDFA) were also measured.

The HKAA was defined as the medial angle formed by the axes that pass through the center of the femoral head, the midpoint between the tips of the tibial spines, and the center of the superior facet of the talus. The angle was assigned a negative value if it was less than $180^{\circ}$ (varus alignment) whereas a positive value was given if it was greater than $180^{\circ}$ (valgus alignment). The MPTA was measured as the medial angle between the mechanical tibial axis and the knee joint line of the proximal tibia. The angle lesser than $90^{\circ}$ represent a varus alignment, and the angle greater than $90^{\circ}$ a valgus alignment. Three points were marked on the femoral shaft as follows, the midpoint of the medullary canal at the lower junction of the lesser trochanter (proximal femoral point), the midpoint of the medullary canal $10 \mathrm{~cm}$ proximal to the knee joint (distal femoral point), and a point midway between the proximal and the distal femoral points (middle femoral point). The FAMA was calculated as the angle formed between the femoral mechanical axis and the femoral anatomical axis which is the line from the proximal femoral point to the distal femoral point. The FBA was determined as the angle between the line from the proximal femoral point to the middle femoral point and the line from middle femoral point to the distal femoral point. Negative and positive values indicated varus and valgus femoral bowing, respectively. The mLDFA was measured as the lateral angle be-

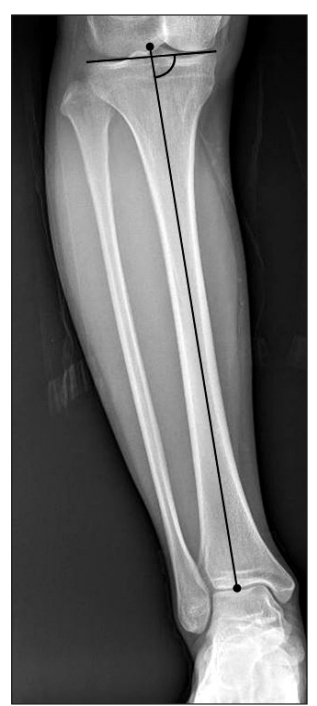

Fig. 2. Medial proximal tibia angle. 


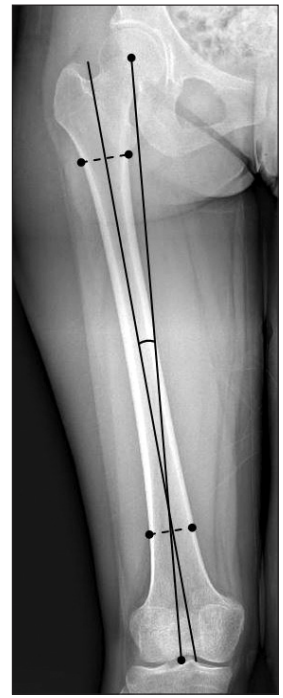

Fig. 3. Femoral anatomic mechanical angle.

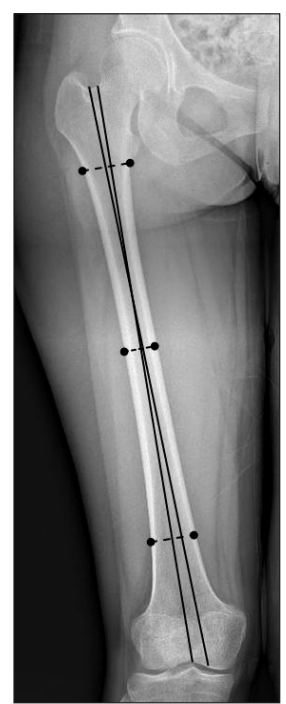

Fig. 4. Femoral bowing angle.

tween the femoral mechanical axis and the joint line of the distal femur (Figs. 1-5).

For statistical analysis, categorical variables were described as frequency and percentage while continuous variables were expressed as mean \pm standard deviation (SD). An intraclass correlation coefficients (ICCs) was used to determine the interobserver reliability. The ICC was calculated using a two-way mixed model with a consistency definition. A one-sample t-test was used for comparison between the values of the continuous variables and the standard values (HKAA, $0^{\circ}$; MPTA, $3^{\circ}$ varus; and FAMA, $6^{\circ}$ ). All statistical analysis was performed using SPSS ver. 21.0 (IBM Corp., Armonk, NY, USA) and p-value of less than 0.05 was

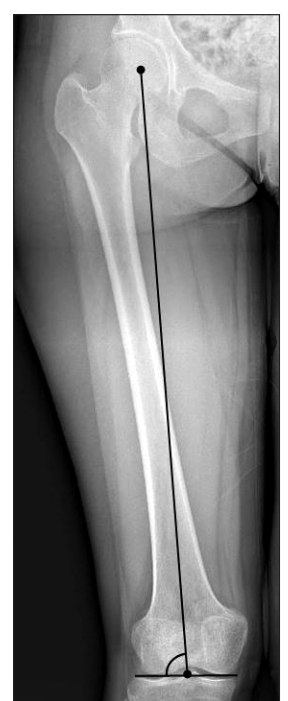

Fig. 5. Mechanical lateral distal femoral angle.

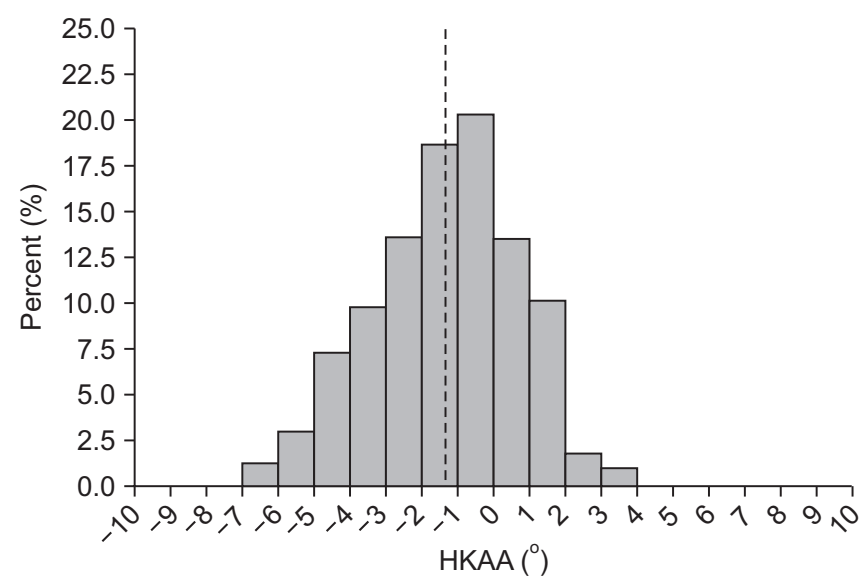

Fig. 6. The histogram shows the distribution of hip-knee-ankle angle (HKAA) in the 236 knees. The mean HKAA was $1.35^{\circ}$ varus (dotted line).

taken as significant.

\section{Results}

The ICCs for HKAA and MPTA were 0.967 and 0.933, respectively, indicating excellent interobserver reliability. The ICCs for FAMA, FBA, and mLDFA were 0.797, 0.866, and 0.811, respectively, showing excellent $(>0.79)$ interobserver reliability. Thus, the reliability of measurements was statistically significant for all continuous variables $(\mathrm{p}<0.001)$ (Table 2$)$. The mean HKAA was $-1.35^{\circ}\left(\mathrm{SD}, 2.04^{\circ}\right)$ (Fig. 6), the mean MPTA was $-3.18^{\circ}\left(\mathrm{SD}, 1.61^{\circ}\right.$ ), the mean FAMA was $5.99^{\circ}\left(\mathrm{SD}, 0.70^{\circ}\right)$, the mean FBA was $1.96^{\circ}$ $\left(\mathrm{SD}, 1.53^{\circ}\right)$, and the mean $\mathrm{mLDFA}$ was $87.78^{\circ}\left(\mathrm{SD}, 1.68^{\circ}\right)$ (Table 2). The one-sample $t$-test for comparison of the mean HKAA, 
Table 2. Radiographic Parameters and Interobserver Reliability

\begin{tabular}{|c|c|c|c|c|c|c|c|}
\hline Variable & No. of cases & Total & Observer 1 & Observer 2 & Observer 3 & ICC & $95 \%$ CI \\
\hline \multicolumn{8}{|l|}{ HKAA $\left({ }^{\circ}\right)$} \\
\hline $\mathrm{R}$ & 118 & $-1.53 \pm 2.07$ & $-1.56 \pm 2.15$ & $-1.61 \pm 2.09$ & $-1.42 \pm 2.04$ & 0.989 & $0.985,0.992$ \\
\hline $\mathrm{L}$ & 118 & $-1.17 \pm 1.99$ & $-1.12 \pm 2.25$ & $-1.25 \pm 2.17$ & $-1.15 \pm 1.88$ & 0.943 & $0.923,0.959$ \\
\hline Total & 236 & $-1.35 \pm 2.04$ & $-1.34 \pm 2.21$ & $-1.43 \pm 2.13$ & $-1.29 \pm 1.96$ & 0.967 & $0.959,0.974$ \\
\hline \multicolumn{8}{|l|}{$\operatorname{MPTA}\left({ }^{\circ}\right)$} \\
\hline $\mathrm{R}$ & 118 & $-3.18 \pm 1.60$ & $-3.36 \pm 1.85$ & $-3.03 \pm 1.79$ & $-3.17 \pm 1.44$ & 0.931 & $0.906,0.950$ \\
\hline $\mathrm{L}$ & 118 & $-3.18 \pm 1.63$ & $-3.03 \pm 1.72$ & $-3.24 \pm 1.84$ & $-3.28 \pm 1.61$ & 0.941 & $0.920,0.957$ \\
\hline Total & 236 & $-3.18 \pm 1.61$ & $-3.19 \pm 1.79$ & $-3.13 \pm 1.81$ & $-3.22 \pm 1.52$ & 0.933 & $0.917,0.947$ \\
\hline \multicolumn{8}{|l|}{ FAMA $\left({ }^{\circ}\right)$} \\
\hline $\mathrm{R}$ & 118 & $6.07 \pm 0.66$ & $6.26 \pm 0.73$ & $6.01 \pm 0.78$ & $5.93 \pm 0.83$ & 0.800 & $0.728,0.855$ \\
\hline $\mathrm{L}$ & 118 & $5.92 \pm 0.73$ & $6.17 \pm 0.83$ & $5.80 \pm 0.78$ & $5.79 \pm 0.99$ & 0.792 & $0.717,0.849$ \\
\hline Total & 236 & $5.99 \pm 0.70$ & $6.22 \pm 0.78$ & $5.91 \pm 0.79$ & $5.86 \pm 0.92$ & 0.797 & $0.748,0.838$ \\
\hline \multicolumn{8}{|l|}{$\operatorname{FBA}\left({ }^{\circ}\right)$} \\
\hline $\mathrm{R}$ & 118 & $2.02 \pm 1.37$ & $2.03 \pm 1.51$ & $1.91 \pm 1.48$ & $2.12 \pm 1.65$ & 0.867 & $0.819,0.904$ \\
\hline $\mathrm{L}$ & 118 & $1.90 \pm 1.35$ & $1.83 \pm 1.54$ & $1.86 \pm 1.42$ & $2.01 \pm 1.59$ & 0.865 & $0.817,0.903$ \\
\hline Total & 236 & $1.96 \pm 1.53$ & $1.93 \pm 1.52$ & $1.89 \pm 1.45$ & $2.06 \pm 1.62$ & 0.866 & $0.833,0.893$ \\
\hline \multicolumn{8}{|c|}{$\operatorname{mLDFA}\left({ }^{\circ}\right)$} \\
\hline $\mathrm{R}$ & 118 & $87.82 \pm 1.66$ & $87.80 \pm 1.52$ & $87.95 \pm 1.85$ & $87.73 \pm 1.45$ & 0.804 & $0.718,0.886$ \\
\hline $\mathrm{L}$ & 118 & $87.75 \pm 1.70$ & $87.75 \pm 1.61$ & $87.84 \pm 1.79$ & $87.71 \pm 1.52$ & 0.820 & $0.728,0.894$ \\
\hline Total & 236 & $87.78 \pm 1.68$ & $87.78 \pm 1.57$ & $87.89 \pm 1.89$ & $87.72 \pm 1.49$ & 0.811 & $0.725,0.893$ \\
\hline
\end{tabular}

Values are presented as mean \pm standard deviation. $\mathrm{p}<0.001$.

ICC: intraclass correlation coefficient, CI: confidence interval, HKAA: hip-knee-ankle angle, R: right, L: left, MPTA: medial proximal tibial angle, FAMA: femoral anatomic mechanical angle, FBA: femoral bowing angle, mLDFA: mechanical lateral distal femoral angle.

Table 3. One-Sample T-Test

\begin{tabular}{cccc}
\hline Variable & No. of cases & Mean \pm SD & p-value \\
\hline HKAA $^{\text {a) }}\left(^{\circ}\right)$ & & & \\
R & 118 & $-1.53 \pm 2.07$ & $<0.001$ \\
L & 118 & $-1.17 \pm 1.99$ & $<0.001$ \\
Total & 236 & $-1.35 \pm 2.04$ & $<0.001$ \\
MPTA $^{\text {b) }}\left({ }^{\circ}\right)$ & & & \\
R & 118 & $-3.18 \pm 1.60$ & 0.215 \\
L & 118 & $-3.18 \pm 1.63$ & 0.230 \\
Total & 236 & $-3.18 \pm 1.61$ & 0.083 \\
FAMA $^{\text {c) }}\left({ }^{\circ}\right)$ & & & \\
R & 118 & $6.07 \pm 0.66$ & 0.271 \\
L & 118 & $5.92 \pm 0.73$ & 0.236 \\
Total & 236 & $5.99 \pm 0.70$ & 0.887 \\
\hline
\end{tabular}

SD: standard deviation, HKAA: hip-knee-ankle angle, R: right, L: left, MPTA: medial proximal tibial angle, FAMA: femoral anatomic mechanical angle.

${ }^{\text {a) }}$ Compared to 0 degree.

${ }^{\text {b) }}$ Compared to -3 degree.

${ }^{c)}$ Compared to 6 degree.
Table 4. Distribution of Hip-Knee-Ankle Angle

\begin{tabular}{lccc}
\hline \multicolumn{1}{c}{ Variable } & $\begin{array}{c}\text { No. of right limbs (\%) } \\
(\mathrm{n}=118)\end{array}$ & $\begin{array}{c}\text { No. of left limbs }(\%) \\
(\mathrm{n}=118)\end{array}$ & $\begin{array}{c}\text { Total (\%) } \\
(\mathrm{n}=236)\end{array}$ \\
\hline Less than $-3^{\circ}$ & $29(24.58)$ & $19(16.10)$ & $48(20.34)$ \\
$3^{\circ}-0^{\circ}$ & $63(53.39)$ & $64(54.24)$ & $127(53.81)$ \\
$0^{\circ}-3^{\circ}$ & $25(21.17)$ & $34(28.81)$ & $59(25.00)$ \\
${\text { More than } 3^{\circ}}$ & $1(0.85)$ & $1(0.85)$ & $2(0.85)$ \\
\hline
\end{tabular}

MPTA, and FAMA values against the standard values (HKAA, $0^{\circ}$; MPTA, $-3^{\circ}$; and FAMA, $6^{\circ}$ ) showed a statistically significant difference for the HKAA $(\mathrm{p}<0.001)$. However, no significant difference was observed with regard to the MPTA $(p=0.083)$ and the FAMA ( $\mathrm{p}=0.887$ ) (Table 3 ). The HKAA, indicating the overall axis of the lower limb, was within the range of $-3^{\circ}$ to $+3^{\circ}$ in 186 knees (78.81\%), below $-3^{\circ}$ in 48 knees $(20.34 \%)$, and over $+3^{\circ}$ in 2 knees $(0.85 \%)$. The incidence of constitutional varus knees with $\geq 3^{\circ}$ varus alignment was relatively high in the study participants $(20.34 \%)$ compared to that in western females (17.2\%) (Table 4). 


\section{Discussion}

With the advent of patient specific implants for TKA, the concept of natural anatomic alignment has been growing interest as an alternative to neutral mechanical alignment ${ }^{7,8)}$. In addition, an increasing number of surgeons have begun to question the importance of restoration of neutral mechanical alignment in patients who have had varus alignment since the attainment of skeletal maturity ${ }^{6}$. Therefore, we investigated whether normal Korean females had neutral mechanical alignment (HKAA, $0^{\circ}$; MPTA, $3^{\circ}$ varus; and FAMA, $6^{\circ}$ ) and the incidence of constitutional varus knees among them.

Our results showed that the MPTA and FAMA in the study participants were not significantly different from the standard values. The FBA was in slight valgus (mean value, $1.96^{\circ}$ ), and the mean mLDFA $\left(87.78^{\circ}\right)$ was not significantly different from the other studies. However, the mean HKAA was slightly in varus deviation $\left(-1.35^{\circ} \pm 2.04^{\circ}\right)$. That results was different from the known neutral axis of $0^{\circ}$ and showed a statistically significant difference $(\mathrm{p}<0.001)$. The presence of slight varus deviation from neutral mechanical alignment has been reported in many studies. Moreland et al. ${ }^{9)}$ reported a mean of $1.3^{\circ}$ varus alignment in normal western males and Hsu et al. ${ }^{10)}$ noted a mean of $2.3^{\circ}$ varus alignment in western males and $1.3^{\circ}$ varus alignment in western females. Tang et al. ${ }^{11)}$ reported that a mean of $2.2^{\circ}$ varus alignment was observed in a Chinese population regardless of gender. Bellemans et al. ${ }^{6}$ documented that constitutional varus alignment ( $\geq 3^{\circ}$ varus deviation) was observed in $17.2 \%$ of the western female knees. In our study, the incidence of constitutional varus alignment (20.34\%) was relatively high compared to that in the above mentioned study.

Factors associated with constitutional varus alignment including increased femoral varus bowing, an increased varus femoral neck-shaft angle, and an increased femoral anatomic mechanical angle were considered ${ }^{12)}$. However, Shetty et al. ${ }^{13)}$ showed that the HKAA was most positively correlated with the MPTA in Indian and Korean adults, whereas there was no significant correlation with BMI, femoral bowing, and femoral neck-shaft angle. According to Bellemann et al. ${ }^{6}$ constitutional varus alignment was associated with increased sports activity during the growth spurt in the teenage years, whereas no significant correlation was established with weight, body type, and BMI. In particular, intense sports activity at the end of the growth spurt (range, 14 to 16 years) imposes biomechanical overload on the medial physis in the proximal tibia, resulting in the development of varus knees ${ }^{14}$. This can be explained by Hueter-Volkmann's law stating that growth at the physes is retarded under increased compression, whereas accelerated under reduced loading. Such unbalanced stress on the epiphysis has also been associated with tibia vara in children ${ }^{15}$. Some studies also suggested that vitamin D insufficiency in children could cause coronal bowing of the femoral shaft, coxa vara, and proximal tibia vara, eventually resulting in constitutional varus alignment ${ }^{16,17}$. Nagamine et al. ${ }^{18)}$ reported that medial torsion of the proximal tibia during kneeling and squatting in childhood in Asian countries with floor-sitting lifestyle resulted in high prevalence of varus alignment compared to that in the Western countries. Likewise, although constitutional varus alignment has been addressed in a variety of studies, consensus is elusive; therefore, further studies are required.

Numerous studies have demonstrated the importance of correcting the mechanical alignment to $0^{\circ} \pm 3^{\circ}$ relative to the neutral axis ${ }^{19,20}$. However, Parratte et al. ${ }^{21)}$ reported that the incidence of revision at 15 years after TKA was not significantly different irrespective of the extent of deviation from the neutral mechanical axis: revision was required in $15.4 \%$ in the mechanically aligned group with a mechanical axis of $0^{\circ} \pm 3^{\circ}(\mathrm{n}=292)$ and in $13 \%$ in the outlier group with a mechanical axis of beyond $0^{\circ} \pm 3^{\circ}(n=106)$. Therefore, they concluded that the mechanical axis goal of $0^{\circ} \pm 3^{\circ}$ had little practical value for predicting the longevity of TKA implants. In addition, the relationship between the outlier (beyond $0^{\circ} \pm 3^{\circ}$ deviation from the neutral mechanical axis) and the survival of TKA implants or clinical outcomes has been shown weak correlations in some other studies ${ }^{22-25}$. In our opinion, these studies suggest the need to reconsider whether restoration of neutral mechanical alignment and avoidance of outlier should also be applied to patients with constitutional varus knees. Based on literature review, Bourne et al. ${ }^{26)}$ reported that various factors, such as patient selection, surgical technique, and implant design, appeared to have an influence on dissatisfaction after TKA that was noted in $11 \%$ to $25 \%$ of the patients. Still, we believe that careful consideration should be given as to whether such patient dissatisfaction could be attributable to the stereotypical goal of restoring neutral mechanical alignment that does not accommodate anatomical variations of patients.

There are some limitations of this study. First, there could have been some measurement errors caused by rotation of the lower limb or the observers; however, we attempted to eliminate errors by taking radiographs in the same position, excluding volunteers with anatomical or congenital deformity to prevent errors due to rotation, and obtaining measurements from three observers to improve reliability. Second, all the study subjects were female. This was because the prevalence of TKA indicated for osteoar- 
thritis was overwhelmingly high in females than men (9:1) in Korea. ${ }^{27)}$ We think further research involving male adults should also be conducted. Third, given the rapid economic development along with changes in lifestyle and diet in the past 50 years, it should be taken into consideration that there must be differences in the body shape, constitution, lifestyle, and nutrition between the current TKA candidates and the study participants.

There is a growing interest in the concept of constitutional varus alignment. We believe that restoration of the original knee alignment based on thorough preoperative and intraoperative assessment of patient's anatomical characteristics would be more beneficial in terms of clinical outcomes and longevity of TKA than the traditional approach aimed at restoring stereotyped neutral mechanical alignment. We hope our findings will encourage further studies.

\section{Conclusions}

In our study, the mechanical axis of the lower limb was in slight varus $\left(1.35^{\circ} \pm 2.04^{\circ}\right)$ in the 118 Korean females in their 20 s and $30 \mathrm{~s}$ and the incidence of constitutional varus alignment was $20.34 \%$. These findings may be useful in reconstruction procedures of the knee, including TKA, unicompartmental knee arthroplasty, and high tibial osteotomy.

\section{Conflict of Interest}

No potential conflict of interest relevant to this article was reported.

\section{References}

1. Fang DM, Ritter MA, Davis KE. Coronal alignment in total knee arthroplasty: just how important is it? J Arthroplasty. 2009;24(6 Suppl):39-43.

2. Berend ME, Ritter MA, Meding JB, Faris PM, Keating EM, Redelman R, Faris GW, Davis KE. Tibial component failure mechanisms in total knee arthroplasty. Clin Orthop Relat Res. 2004;(428):26-34.

3. Collier MB, Engh CA Jr, McAuley JP, Engh GA. Factors associated with the loss of thickness of polyethylene tibial bearings after knee arthroplasty. J Bone Joint Surg Am. 2007; 89:1306-14.

4. D'Lima DD, Hermida JC, Chen PC, Colwell CW Jr. Polyethylene wear and variations in knee kinematics. Clin Orthop Relat Res. 2001;(392):124-30.
5. Liau JJ, Cheng CK, Huang CH, Lo WH. The effect of malalignment on stresses in polyethylene component of total knee prostheses: a finite element analysis. Clin Biomech (Bristol, Avon). 2002;17:140-6.

6. Bellemans J, Colyn W, Vandenneucker H, Victor J. The Chitranjan Ranawat award: is neutral mechanical alignment normal for all patients? The concept of constitutional varus. Clin Orthop Relat Res. 2012;470:45-53.

7. Howell SM, Howell SJ, Kuznik KT, Cohen J, Hull ML. Does a kinematically aligned total knee arthroplasty restore function without failure regardless of alignment category? Clin Orthop Relat Res. 2013;471:1000-7.

8. Howell SM, Hull ML. Kinematic alignment in total knee arthroplasty. In: Scott WN, Insall JN, eds. Insall \& Scott surgery of the knee. 5th ed. Philadelphia, PA: Elsevier/Churchill Livingstone; 2012. p1255-68.

9. Moreland JR, Bassett LW, Hanker GJ. Radiographic analysis of the axial alignment of the lower extremity. J Bone Joint Surg Am. 1987;69:745-9.

10. Hsu RW, Himeno S, Coventry MB, Chao EY. Normal axial alignment of the lower extremity and load-bearing distribution at the knee. Clin Orthop Relat Res. 1990;(255):215-27.

11. Tang WM, Zhu YH, Chiu KY. Axial alignment of the lower extremity in Chinese adults. J Bone Joint Surg Am. 2000;82: 1603-8.

12. Victor J, Urlus M, Bellemans J, Fabry G. Femoral intramedullary instrumentation in total knee arthroplasty: the role of pre-operative X-ray analysis. Knee. 1994;1:123-5.

13. Shetty GM, Mullaji A, Bhayde S, Nha KW, Oh HK. Factors contributing to inherent varus alignment of lower limb in normal Asian adults: role of tibial plateau inclination. Knee. 2014;21:544-8.

14. Witvrouw E, Danneels L, Thijs Y, Cambier D, Bellemans J. Does soccer participation lead to genu varum? Knee Surg Sports Traumatol Arthrosc. 2009;17:422-7.

15. Cook SD, Lavernia CJ, Burke SW, Skinner HB, Haddad RJ Jr. A biomechanical analysis of the etiology of tibia vara. J Pediatr Orthop. 1983;3:449-54.

16. Marwaha RK, Tandon N, Reddy DR, Aggarwal R, Singh R, Sawhney RC, Saluja B, Ganie MA, Singh S. Vitamin D and bone mineral density status of healthy schoolchildren in northern India. Am J Clin Nutr. 2005;82:477-82.

17. Kim SH, Oh MK, Namgung R, Park MJ. Prevalence of 25-hydroxyvitamin D deficiency in Korean adolescents: association with age, season and parental vitamin D status. Public Health Nutr. 2014;17:122-30. 
18. Nagamine R, Miyanishi K, Miura H, Urabe K, Matsuda S, Iwamoto Y. Medial torsion of the tibia in Japanese patients with osteoarthritis of the knee. Clin Orthop Relat Res. 2003;(408):218-24.

19. Jeffery RS, Morris RW, Denham RA. Coronal alignment after total knee replacement. J Bone Joint Surg Br. 1991;73:70914.

20. Choong PF, Dowsey MM, Stoney JD. Does accurate anatomical alignment result in better function and quality of life? Comparing conventional and computer-assisted total knee arthroplasty. J Arthroplasty. 2009;24:560-9.

21. Parratte S, Pagnano MW, Trousdale RT, Berry DJ. Effect of postoperative mechanical axis alignment on the fifteen-year survival of modern, cemented total knee replacements. J Bone Joint Surg Am. 2010;92:2143-9.

22. Bonner TJ, Eardley WG, Patterson P, Gregg PJ. The effect of post-operative mechanical axis alignment on the survival of primary total knee replacements after a follow-up of 15 years. J Bone Joint Surg Br. 2011;93:1217-22.
23. Lee HJ, Jung HJ, Jung YB, Ko YB, Song MK, Kim SH. Timedependent clinical results of rotating-platform total knee arthroplasty according to mechanical axis deviation. Knee Surg Relat Res. 2014;26:141-8.

24. Matziolis G, Adam J, Perka C. Varus malalignment has no influence on clinical outcome in midterm follow-up after total knee replacement. Arch Orthop Trauma Surg. 2010;130: 1487-91.

25. Morgan SS, Bonshahi A, Pradhan N, Gregory A, Gambhir A, Porter ML. The influence of postoperative coronal alignment on revision surgery in total knee arthroplasty. Int Orthop. 2008;32:639-42.

26. Bourne RB, Chesworth BM, Davis AM, Mahomed NN, Charron KD. Patient satisfaction after total knee arthroplasty: who is satisfied and who is not? Clin Orthop Relat Res. 2010;468:57-63.

27. Koh IJ, Kim TK, Chang CB, Cho HJ, In Y. Trends in use of total knee arthroplasty in Korea from 2001 to 2010. Clin Orthop Relat Res. 2013;471:1441-50. 